\title{
The cultural dialogue on the domestic dimension of care to immigrant caregivers in Spain ${ }^{1}$
}

\author{
Isabel Morales-Moreno² \\ Maravillas Giménez-Fernández ${ }^{2}$ \\ Paloma Echevarría-Pérez ${ }^{2}$
}

\begin{abstract}
Objectives: to determine how the immigration phenomenon influences the response to informal care in the domestic level through the caregiver activity, and to analyze the cultural dialogue established in the residential area of Murcia (Spain). Method: This is an ethnographic study, conducted in 26 informal immigrant caregivers. As data collection instruments, semi-structured interviews and participant observation were employed. MAXQDA-2 assisted content analysis was also applied. Results: the immigrant caregiver is the main consumer of traditional medicines, extending these health practices to her home group. A cultural dialogue is established on informal care, characterized by interculturalism and mutual adaptation. Conclusions: cultural hybridization was identified for informal caregivers, immigrants and cultural integration: new health care practices and cultural behaviors in informal systems. There is a transformation in the roles of family members attended in domestic environments, increasing quality of life and self care. They represent an alternative to medicalization, promoting self-management of health.
\end{abstract}

Descriptors: Caregivers; Medicine, Traditional; Cultural Evolution; Cultural Competence; Self Care.

\footnotetext{
1 Paper extracted from doctoral dissertation "Cultural dialogue in domestic care dimension: analysis of cultural heritage, cultural care and selfcare in immigrant caregivers" presented to Universidad Católica de Murcia, Murcia, Spain.

2 PhD, Professor, Facultad de Enfermería, Universidad Católica de Murcia, Murcia, Spain.
}

Corresponding Author: Isabel Morales Moreno

Universidad Católica de Murcia. Facultad de Enfermería

Campus de Los Jerónimos, $\mathrm{s} / \mathrm{n}$

Bairro: Guadalupe

CP: 30107, Murcia, España

E-mail: imorales@ucam.edu
Copyright () 2015 Revista Latino-Americana de Enfermagem This is an Open Access article distributed under the terms of the Creative Commons Attribution Non-Commercial License (CC BY-NC).

This license lets others distribute, remix, tweak, and build upon your work non-commercially, and although their new works must also acknowledge you and be non-commercial, they don't have to license their derivative works on the same terms. 


\section{Introduction}

The experiences of health and human disease is a process that can be understood as a continuum. The evolution of the person to the end of the disease involves a number of health practices supported by knowledge and cultural beliefs that often replace or continue the care given by a health care professional, established according to the biomedical model. Until the moment the health care contact begins, the informal care systems and processes for self care thrive and develop themselves. Both of them are essential, however simultaneous professional care is also demanded. The care provided at home have historically been assumed by women, with important implications concerning gender.

In Europe, the aging population, increasing life expectancy and the growing number of people with chronic and disabling diseases directly affect the demand for informal care at home, but it has also affected the structures and forms of family life. The availability of caregivers is seriously threatened by: the progressive incorporation of women in the labor market, the mobility of family members and the smaller size of houses ${ }^{(1)}$. Aging and the incorporation of women in the labor market are contemporary to an important migratory phenomenon in Spain. The result is the evolution of informal care systems, now undertaken largely by immigrant women, who take on the role of informal caregiver for the family, playing a traditional scheme of care.

Social scientists should study the actual contexts, everyday interactions and processes of mediation and integration, analyzing all dimensions in which this social phenomenon develops itself, to understand and address possible improvements and its articulation with the formal care sector. Therefore, we consider essential to approach a phenomenon that affects family dynamics and the satisfaction of the dependent. It is a cultural dialogue established in the natural environment of informal care (domestic) between people with different cultural patterns (dependent person-immigrant caregiver), which represents great potential for mutual enrichment and at the same time favors the knowledge and the development of other health practices that streamline health care pluralism. Currently, the Biomedical system has to return certain functions to the domestic environments of patients, which was taken over by the process of medicalization of natural processes. Many changes converge affecting the provision of health care, on the part both of the formal system of care and the informal one. It is, thus, necessary to rework and analyze new alternatives for the care of dependents in a time when Spain is being oriented to the European Social Model, with its dependent-care policy. However, at the same time, the State does not fully assume the social responsibility for those people, bringing up the State's limit concerning the well-being of these people. We reinforce our argument with the aid of those of other authors, considering that in this new context, the Hegemonic Medical Model denotes failure in the management of cultural meanings in health, expressing both its limitations and the need for new approaches. The biomedical crisis reflects its inadequacy for not keeping a dialectical relationship with the knowledge of the "profane", which would improve the quality of care(2).

\section{General objectives}

To get to know the influence of the phenomenon of immigration, especially its beliefs and practices under domestic informal health care at the national level through the activity of a caregiver, and to analyze the cultural dialogue established between family caregivers, dependent people and immigrants caregivers in the domestic environment.

\section{Specific objectives}

To study the influence and/or changes performed by the immigration phenomenon in family structures and domestic environments. Also, to get to know the systems of beliefs and values that determine health care options performed in modern societies (self care, self treatment, professional systems, alternative systems, traditional medicine etc.)

\section{Method}

We present some results of an ethnographic project of a PhD thesis performed in Murcia (Spain), in 2010. Study population: Murcia families with at least one family caregiver and/or an informal immigrant caregiver. Quantification was not necessary since this was an ethnographic study, highlighting the theoretical value of the speeches. Criteria for inclusion: that the object of care is a member of the family unit that displays chronic problems of health and development over time, with features of permanence and immobility, in need of informal care. Exclusion criteria: that the recipients of informal care were children or people not dependent and/or immobilized. 
Forty-eight extensive interviews were carried out. This paper will discuss only the subgroup of immigrant caregivers sample made up of 26 individuals, coded alphanumerically and according to the data caption. The countries of origin and number of interviewees in each case were: Bolivia (9), Ecuador (8), Colombia (2), Venezuela (2), Romania (2), Honduras (1), Dominican Republic (1) and Peru (1). Participant observation was also applied, following a validated array structure (3). The doormen and key informants were selected by convenience in an evangelical community ("El Rollo") and in a NGO (Cáritas-Murcia); then the snowball sampling technique was applied until achieving saturation.

The research covers four areas: old age, immigration, informal care and cultural dialogue. This paper focus only on the last, which includes four categories of analysis (which has also structured the interview): domestic environment of care, other health care systems, cultural dialogue in informal care and intercultural meeting in informal care with the aid of health care pluralism. The interviews were recorded and transcribed. Content analysis assisted by the MAXQDA-2 software was performed.

\section{Results-Discussion}

The domestic care environment: transformation of the home group and cultural meeting place

Three main types of domestic groups that identify the figure of immigrant caregiver were found. In the first, the immigrant caregiver works in an internal system, and is the only person who does not belong to the family group. In the second, the immigrant caregiver and her family are also in the internal system, in which the dependent person is the only person who does not belong to the family group of the immigrant caregiver. The third type is the one where the immigrant caregiver works in an external system and does not live with the people they care for. This is a new structure that, not being familiar, complies with all its functions, even with no blood ties between the members that compose such family. Many times we identified dependent older adults that lived alone in their homes and were cared by a caregiver immigrant who brought his/her own family, living together in the house of the dependent person. In these cases, great benefits were manifested concerning the service and the quality of life (affective and emotional aspects of care). We observed how the contact of children with older adults, particularly with dementia, clearly reduces aggression episodes. Staying within a family group has clear advantages in these processes. In turn, they allude to kinship terms to identify the roles of each person (grandmother, mother, daughter, granddaughter ...), denoting family aspects and not just domestic partnership. These are the socio-economic units where housing is shared. However, family is an institution or group that coexists and has ties. The new structures present characteristics of both.

[...] Depends on the people you meet; I ate with them at the table, as another member of the family. Soon I had a grandfather who was in his home with my kids... as if we were in the same family [...] well, it seemed like who was internal was the grandfather. (CI-5)

The immigrant caregivers have an ideology of extended family which is reproduced in Spain, replacing some family members in their home countries by people that they care for in Spain. The perception of care for older adults depends on social and cultural aspects of the society of origin, that shapes the values, ideas and representations of the person about the care. Therefore, even in cases of high degree of acculturation concerning immigrants caregivers - in other contexts, such as in the United States -, the ideology of reciprocity and loyalty in the care of older people remains, as in our study(4). An ethos of reciprocity in attendance underlies, with connotations more specific to a family caregiver than to a working relationship, with personal involvement which includes the family institution. The principle of reciprocity, understood as a total social fact connected to the family institution, is confirmed. The presence of transnational movement is also confirmed, taking as analysis unit the caregiver's network, based on a multidimensional vision of care that transcends personal care applied to a dependent person ${ }^{(5)}$. This new model of domestic-familiar group includes variants and changes, defending the functionalism and the family care model. However, in this phenomenon lies an important social change and invisible commodification of informal care. Those are structural changes that reorganize the family institutions towards functionalism, keeping the personal relationship and the humane treatment ${ }^{(6)}$. The internal immigrant caregiver also refers to integration, but more slowly(7-8). The structure of nuclear family, and not extended family, is reproduced, and so the link is smaller than in the previous type. The third type of caregiver (external system) does not involve integration. There are reports of negative experiences of discrimination and even racism. 
[...] I couldn't fit the family because they did not welcome me. (CI-7)

Gender and the position in the social structure due to immigration shape the caregiver's situation in terms of insecurity and inferiority. This situation is very common in other countries in Europe today, as France, Germany, Switzerland and Holland (9). We tried to question the role of dependents who delegate most functions to the immigrant caregiver, and therefore we identified a true replacement of roles related to kinship. However, there are still main family caregivers.

[...]. If you need someone to look after your mother because you have little time, and pay for someone to do it, at least you visit her, when you have a moment to spare... Here I haven't seen this... Here you hire the caregiver to do everything and walk away. (CI-9)

Several studies have shown positive results in terms of informal care when there is an internal foreign caregiver caring for the dependent person, even in remote environments, socially and culturally different from ours, such as Asia(10).

\section{Other health care systems: representations and practices}

To understand the ideas and practices that revolve around the health/disease/care in the case of immigrant caregivers in our environment, it is necessary to know the main features of health care systems in their countries of origin, since the practice of self care and self treatment are determined in large part by them, and tend to be reproduced in the new environment ${ }^{(11)}$. Health practices have diverse characters, scarce in relation to the Biomedical System both by the therapeutic efficacy and cost. Parallel to the development of the scientific medicine, a body of beliefs and practices in relation to health was maintained and developed, supported by the social environment and cultural tradition that has marked the kind of self care and informal care practices of these caregivers. The choice pattern of one system or another is determined mainly by the nature of the health problem.

[...] Two are used, both the natural one and the drugs. (CI-21)

[...] Healers indicate natural medicines, things from the earth that heal more quickly than the medicine of a doctor. Now, if there's an infection or a problem which requires an operation, in this case a healer will not cure you, but there are a lot of things. For example, people who have small tumors like me, I have myoma, have to take a medicine, and they are reduced so completely that I feel no pain or discomfort. I prepare the syrup; raw chopped beets mixed to the syrup gives very good results. (CI-17)

The cultural keys that explain the self treatment phenomenon are reproduced. Latin American societies are characterized by their increasing levels of poverty, by a constant and continuous decapitalization of services and migration, incorporating new standards of self care. This process allows the system to delegate in this structure of self care much of its social and sanitary responsibilities, thereby increasing the importance of self care or allowing it to functionally overtake health care $^{(12)}$.

[...] Yes, yes. Because our country is very poor and we use a lot of herbs. To the baby to whom the milk made him feel sick and left his stomach very bloated, we give solmate de anis. We use a lot of coke as medicine, as well as tobacco for earaches. (CI-11)

The informal caregivers in Spain are mostly Latin American women, and therefore it was possible to recover several already mentioned theoretical approaches $^{(13)}$. The conditions of formal health care determine the proliferation and development of the phenomena of the informal sector self care and self treatment performed by immigrants. This aspect can encourage its development, promoting the reproduction of cultural behavior patterns in relation to health in Spain. But self treatment practices also change, since the knowledge of social groups is not something culturally fixed, it is continuously restructured by new techniques, products and beliefs that are integrated to existing knowledge(12). We noticed complementarity, conflicts and sometimes contradictions, but they coexist and have internal consistency. Those techniques are pragmatic and functional, reflecting a synthesis of knowledge that correspond to various different medical models, such as biomedicine and traditional medicine. It is a fact that demonstrates the cultural dialogue as an example of cultural exchange, fusion, enrichment and hybridization.

[...] Look, if you have an amoeba in the stomach, you should boil the husk of a pomegranate and drink the tea. Spicy garlic tea and carrots also kill parasites. For muscle aches, we use herbs that are not found here. (CI-17)

[...] Sometimes he has stomachache and I make water of oregano and cumin, and it goes away. For example, if your back hurts, we shall give you an eucalyptus cream that we brought from our country, or Chinese menthol, and proceed to apply it. (CI-4)

[...] When my husband or one of us gets sick (including the older adult I take care of), I first use my homemade remedies, 
and only after do I try medicines. I use a lot of herbs, vinegar, garlic... first them, and if it fails, then I'll go to a doctor, but I always try my remedies first. (CI-8)

[...] In Bolivia we don't go to doctors. My mother-in-law had diabetes, but she never took insulin injections, she took some herbs. She made beaten celery and used a vegetable named choca. There, we cure the cold with onion, garlic and lemon. And there you go! We do not take drugs unless it is a very serious case, just then do we go to the doctor. For gastritis there are also herbs, some leaves called Zen and Ajenco. We don't like drugs. For stomachache, we use Ayaten. There they drink infusions of leaves of tangerine, lemon, avocado water... to the kidneys. Diets like the one of the moon, with a lot of water and things like that. They say that drugs cure you from one thing, but mess with others. (CI-20)

Traditional medicine practices are maintained, both with members of their own families and with the older adults who they care for, taking into account the influence of being internal caregivers and having a certain level of integration. Outside the Spanish environment, immigrants, especially the older ones who come from countries with extensive use of traditional medicine, show their preference for biomedicine. This reality was observed in the USA and Canada, where we find studies that show patterns of use that vary between $77 \%$ and $100 \%$ (in the case of the USA). This is relevant among Asian immigrants in the USA, who claim that it not only has an effect on improving health, but also strengthens ethnic identity(13). In Canada, $73 \%$ of African origin immigrants use traditional medicine, justifying their choice for holism(14-15). In the country, the application of complementary therapies by immigrant caregivers in the people they care for was studied, since this causes a lower frequency of hospital forwarding and use of sanitary services for dependents receiving the care. The immigrant caregivers highlight the lack of support and cultural sensitivity of the social and sanitary services as factors that boost the therapy complementarity which they exercise ${ }^{(16)}$. The intercultural relationship between traditional medicine and biomedicine also allows a holistic health care, promoting welfare pluralism. This phenomenon is a structural factor present in all societies, not only in the area of analysis. In this area, there is insufficient assimilation due to the subordinate character and invisibility that these health practices still have. The combination of knowledge and different health practices enables the identification of a provision of informal care from the immigrants caregivers with holistic range and quality. In relation to ethnography, it is in the domestic environment where an universe of meanings is created, where these practices have high efficacy concerning the complete well-being of the person and also at the symbolic level. However, these are still not shared in larger social structures. We support the holistic view of health as part of a symbolic whole. Informal immigrants caregivers give much importance to the well-being of the individual, to the family and human care component and to the expression of reciprocity in self treatment and self care, because all of this enables the balance and the true welfare to the person who they care for, emphasizing the therapeutic potential of human relationships.

[...] I took care of him, changed his clothes and gave him homemade medicines... I keep taking them and recommend it. (CI-21)

A immigrant caregiver only advises not to apply such practices out of respect for customs and for fear of self medication with phytotherapy, in contrast to the loss of authority that usually occurs with chronic patients.

\section{The cultural dialogue in informal care: opening the way for cultural miscegenation and hybridization}

One may consider that the meeting of cultures is not a generator of conflict, but of cultural dialogue ${ }^{(17)}$. We agree with this approach, because we found little evidence of cultural conflicts through care. Although the informal care provided by immigrant women creates more positive than negative results, the experiences from other countries do not corroborate that, with the occurrence of language problems, as shown in a study conducted in England(18). This aspect does not favor interculturality and miscegenation, but multiculturalism and differentiation. In our case, all but two caregivers were Latin American immigrants. Some spoke other languages or dialects from their hometowns, such as Quechua; the informers who spoke Quechua continued to use that language here, a practice that was sometimes associated with problems of understanding the Spanish language. Regarding language, understood as quality, there are studies about its effect on the therapeutic relationship between immigrant caregivers and dependent people speaking different languages. The fact that both the dependent and the caregiver speak the same language makes the work of caregivers easier(19). It is not realistic to defend cultural diversity absolutely, or to surrender to a global homogenization, believing in the continuous cultural regeneration, diversity and mix in an intercultural global environment. 
The meeting of cultures in informal care as an assistance pluralism booster factor

Immigration has allowed a better understanding of other processes of looking for health, which reaffirms but does not justify the existence of an assistance pluralism model. Traditional medicine is coming out of its original contexts through the phenomenon of migration, and the contact with different cultures provides the proliferation of new intercultural medicine practices $^{(20)}$. Other studies assume the existence of certain biomedical flows from Spain to South America (specifically Ecuador), and not the other way around. However, it was concluded that the flow of shipments and orders for certain products is established mainly to Spain, constituted not only by natural remedies and traditional prevention or healing elements difficult to obtain in Europe, but also by rather common medicines in our midst ${ }^{(12)}$. This flow is evidenced in our study, and shows another form of intercultural meeting through health. To receive products of traditional medicine at a transnational level allows maintaining, producing and reproducing both their own health practices and the underlying ideology. Menéndez would justify this product flow as a structural process developed by biomedicine, as self-medication in relation to selfcare $^{(21)}$. However, these studies have highlighted the great symbolic potential to strengthen the bonds of the large, transnational family, due to its relationship with the sphere of care ${ }^{(22)}$. According to other studies, the ideas in defense of natural products in nonWestern societies were raised in opposition to the toxicity of drugs and lifestyles. So, the idea of nature linked to traditional medicine is often combined with consciousness of class, ethnicity and national identity, opposing the foreign and the artificial, in a sort of health identity policy; expressing skepticism about drugs is a way to build dichotomies such as nature/technology or tradition/modernity(23). These approaches are identified in our ethnography. Many studies show that people belonging to ethnic minorities tend to opt for alternative or traditional medicines as first choice; that option has nothing to do with the need to address the health issues in the context of their own resources and culture/ethnicity. Their beliefs that folk medicine has a certain control over the causes of the disease and lower expenses are some of the reasons for choosing these health practices. There is a widespread belief in Latin America, especially among the elderly, that natural remedies are good because they are innocuous(24).
[...] The elders in my homeland cure arthritis with marijuana and rum; they put it somewhere and let it ferment. Then they drink it, and that's very good. (CI-15)

Our informants also refer to common practices including magic-religious dimensions such as witchdoctoring or prayers.

[...] In addition to homemade remedies, there are many witch doctors. [...] They recommend natural remedies, things from the earth that heal more quickly than medicine from a doctor. (CI-17)

[...] There they use both natural remedies and drugs [...]; yes, they practice witch-doctoring. They pray to ward off evil spirits and some types of diseases, such as the evil eye. Evil exists, and some people believe these things, but if you don't believe them, nothing happens... (CI-21)

WHO institutionally supports worldwide the coexistence of traditional medicine and biomedicine, supporting intercultural understanding between the different conceptions of health and boosting assistance pluralism ${ }^{(25)}$. Addressing the image of the woman as the main consumer of traditional medicines allows proposing she is the one who supplies them and gives them to people she cares for, which perpetuates the invisibility of assistance pluralism. In addition to the integration and coordination, assistance pluralism must make it possible to respond to different ways of thinking and conceiving the process of searching for health, creating an understanding of cultural changes.

\section{Conclusions}

Immigration, specifically of women, is a phenomenon that has created a setting in Spain that offers many possibilities for mutual cultural enrichment, plus numerous ways to enrich, take care of and benefit specifically the dependent group in the household/family environment.

A cultural dialogue is thus established in informal care, characterized by interculturalism and mutual adaptation. Cultural hybridization elements are identified in informal care. The cultural exchange and integration experiences demonstrate the emergence of new assistance care practices in the context of informal care and cultural behaviors in self-care systems.

Immigrant caregivers contribute to the recognition of the use of traditional medicine. Immigrant women in this study stand out as the main consumers of traditional medicines, increasing the offer of these health practices to other members of the family or household under their care, which favors assistance pluralism, but at the same time promotes its invisibility. 
Self-treatment and self-care practices represent an alternative to medicalization, opening new paths toward a greater health self-management phenomenon, characterized by a greater capacity of autonomous decision by domestic care units for a less dependent relationship in relation to social assistance coverage provided by the State.

Knowledge and enlightenment of cultural sensitivity and life experiences on informal care through an ethnographic approach to the real needs of caregivers should be included in the evaluation and formulation of appropriate policies for dependent care.

\section{References}

1. García-Calvente MM, Mateo-Rodríguez I, Eguiguren AP. The system of informal caregiving as inequality. Gac Sanit. 2004;18:132-9.

2. Comelles JM. Cultura y Salud. De la negación al regreso de la cultura en Medicina. Cuaderns ICA. 2003; 19:111-31.

3. Spradley JP. Participant Observation. New York: Holt, Rinehart \& Winston; 1980.

4. Hsueh-Fen SK, Kyungeh A. Effect of acculturation and mutuality on family loyalty among Mexican American caregivers of elders. JNS. 2012;44(2):111-9.

5. Merla L. La circulación de cuidados en familias transnacionales. CIDOB d'Afers Internacionals. 2014;(106107):85-104.

6. Rodríguez-Rodríguez V. Inmigración y cuidados de mayores en los hogares de la comunidad de Madrid [Internet]. Homepage of Portal de Mayores - 2010. 2010 [acesso 4 fev 2010] Disponível em: http://www. imsersomayores.csic.es/documentos/documentos/ rodríguez-inmigración-01.pdf

7. Martínez-Buján R. Los beneficios de la inmigración al Estado de Bienestar. Mujeres inmigrantes en el sector doméstico de cuidados. En: Izquierdo A. El modelo de la inmigración y los riesgos de exclusión. Madrid: Cáritas Española; 2009.

8. Oliver-Alonso J. El mercado de trabajo de la inmigración 2007-2010. Los cambios 2009/2010 en el marco de la crisis. Em: Aja E, Arango J, Oliver J. Inmigración y crisis económica. Impactos actuales y perspectivas de futuro. Barcelona: Bellaterra; 2011. p. 131-64.

9. Le Bihan B, Martin C, Knijn T. Work and care under pressure: Care arrangements across Europe. Amsterdam: Amsterdam University Press; 2013 10. Ostbye T, Malhotra R, Malhotra C, Arambepola C, Chan A. Does support from foreign domestic workers decrease the negative impact of informal caregiving? Results from Singapore survey on informal caregiving. J Gerontol B Psychol Sci Soc Sci. 2013;68(4):609-21.

11. Meñaca A. La "multiculturalidad" de la biomedicina. El envío de medicamentos en familias migrantes ecuatorianas. Em: Fernández-Juárez G. Salud e Interculturalidad en América Latina. Antropología de la salud y crítica intercultural. Cuenca: Universidad Castilla-La Mancha; 2006. p. 93-108.

12. Menéndez E. Autoatención y participación social: estrategias o instrumentos en las políticas de atención primaria. Em: Roersch C. Medicina tradicional, 500 años después. Santo Domingo: Instituto de Medicina Dominicana; 1993. p. 63-104.

13 Chung AY. From caregivers to caretakers: the impact of family roles on ethnicity among children of Korean and Chinese immigrant families. Qual Sociol. 2013;36:279302.

14. Wu APW, Burke A, LeBaron S. Use of Traditional Medicine by immigrants chinese patients. Fam Med. 2007;39(3):195-200.

15. Barimah KB, Van Teijlingen ER. The use of Traditional Medicine by Ghanaians in Canada. BMC Complement Altern Med. 2008;8(30):1-20.

16. Stewart MJ, Neufeld A, Harrison MJ, Spitzer D, Hughes K, Makwarimba E. Immigrant women family caregivers in Canada: Implications for policies and programmes in health and social sectors. Health Soc Care Comm. 2006; 14(4):329-40.

17. Uribe-Oyarbide JM. Migraciones y salud. Préstamos de ida y vuelta. Em: Fernández-Juárez G. Salud e Interculturalidad en América Latina. Antropología de la Salud y Crítica Intercultural. Cuenca: Universidad de Castilla-La Mancha; 2006. p. 83-92.

18. Department of Health and Social Services Inspectorate. Women in social services, London (UK): Department of Health and Social Services Inspectorate; 1991

19. Ekman SL. Monolingual and bilingual communication between patients with dementia diseases and their caregivers. Int Psychogeriatr. 1996;8(1):127-32.

20. Aparicio-Mena AJ. La Antropología aplicada, la medicina tradicional y los sistemas de cuidado natural de la salud. Una ayuda intercultural para los padecimientos crónicos. Gaz Antropol. 2007;23:23-14.

21. Menéndez E. Intentionality, experience and function: the shaping of medical knowledge. Rev Antropol Soc. 2005;14:33-69.

22. Meñaca A. Salud y migraciones. En Fernández Juárez G. Salud e interculturalidad en América Latina. Quito: Ayala, UCLM, Bolhispania; 2004. p. 53-65. 
23. Reynolds-Whyte S, Van der Geest S, Hardon A. Social lives of medicines, Cambridge (UK): Cambridge University Press; 2002.

24. Lima SC, Arruda G, Renovato R, Alvarenga MR. Representations and uses of medicinal plants by elderly. Rev. Latino-Am. Enfermagem. 2012;20(4):778-86.

25. Organización Mundial de la Salud. Estrategia sobre Medicina Tradicional. [Internet]. 2010. [acesso 7 jul 2010]; Disponível em: http://apps.who.int/gb/ebwha/ pdf_files/EB124/B124_R9-sp.pdf 